\title{
Effect of Solution Treatment and Cooling Rate on the Microstructure and Hardness of Ti-6AI-4V Alloy Manufactured by Selective Laser Melting Before and After Hot Isostatic Pressing Treatment
}

\author{
Naeem Eshawish, Savko Malinov, and Wei Sha
}

Submitted: 3 August 2021 / Revised: 16 November 2021 / Accepted: 24 November 2021 / Published online: 31 January 2022

\begin{abstract}
This paper extends our previous work to investigate the effect of heat treatment on the microstructure of Ti6Al-4V fabricated by selective laser melting. A post-heat treatment at $930{ }^{\circ} \mathrm{C}$ for 15 min followed by three cooling rates before and after hot isostatic pressing (HIP) treatment was applied. The findings illustrated that the microstructure of the quenched samples before the HIP treatment was characterized by a mixture of $\alpha+\alpha^{\prime}$ phase with a microhardness value of $336 \pm 6 \mathrm{HV} 0.3$. Air cooling produced a structure dominated by the $\alpha$ phase, with $\sim 7.5 \%$ of the $\beta$ phase and a microhardness value of about $330 \pm 4$ HV0.3. Furnace cooling led to a mixture of $\alpha$ phase and $\sim 17 \%$ of the $\beta$ phase and hardness of $327 \pm 6 \mathrm{HVO} .3$. After HIP followed by post-heat treatment, acicular $\alpha^{\prime}$ martensite with microhardness value $377 \pm 2$ HVV.3 dominated the quenched specimen microstructure. Following air cooling, the microstructure consisted of a mixture of $\alpha$-lamella and $\beta$ with some needles of the $\alpha$ with a microhardness value of $336 \pm 3 \mathrm{HVO}$. In the case of the furnace cooling, a complete transformation of $\beta$ to a mixture of $\alpha+\beta$ phase was observed. The $\beta$ volume fraction formed in the microstructure was estimated at $\sim 8.5 \%$, having microhardness $322 \pm 4$ HV0.3. Reasons for such behaviors are discussed.
\end{abstract}

Keywords cooling rates, heat treatment, phase transformation, SLM, Ti-6Al-4V

\section{Introduction}

The aerospace and medical sectors are constantly developing new designs to achieve weight reduction and higher productivity, performance and safety requirements. As a result, advanced manufacturing techniques complement conventional manufacturing to meet these strict requirements (Ref 1,2). Selective laser melting (SLM) is one of such techniques with a superior capability of manufacturing three-dimensional structures with geometrically complex shapes using less material and producing less waste (Ref 3 ). Moreover, it can potentially drive down cost and weight and achieve acceptable geometric accuracy levels (Ref 4).

The SLM Ti-6Al-4V alloy is being used in different applications due to its low Young's modulus, high strengthto-weight ratio and high corrosion resistance (Ref 5-7). However, in terms of microstructure characterization, its

Naeem Eshawish and Savko Malinov, School of Mechanical and Aerospace Engineering, Queen's University Belfast, Belfast BT7 1NN, UK; and Wei Sha, School of Natural and Built Environment, Queen's University Belfast, Belfast BT7 1NN, UK. Contact e-mails: neshawish01@qub.ac.uk, w.sha@qub.ac.uk.

$$
\text { s.malinov@qub.ac.uk, and }
$$

response to heat treatment differs significantly from conventionally processed Ti-6Al-4V alloy (Ref 5, 8, 9).

SLM Ti-6Al-4V parts usually suffer from high residual stress, porosity, surface roughness, segregation phenomena and typically possess acicular $\alpha^{\prime}$ martensite microstructure due to rapid solidification, hence, low ductility (Ref 10-12). Other reports indicated $\alpha^{\prime}$ and some $\beta$ in the as-produced alloy (Ref 13, 14). Recently, Ali et al. (Ref 15) measured the residual stress in SLM Ti-6Al-4V samples, and they found that preheating the base plate to $570{ }^{\circ} \mathrm{C}$ can eliminate in-built residual stresses and improve ductility. Furthermore, the lowest residual stress value was found with an energy density of $76.9 \mathrm{~J}$ $\mathrm{mm}^{-3}, 133 \mu$ s exposure time and $150 \mathrm{~W}$ power. Another study by Ali et al. (Ref 16) also found that the layer thickness has an inverse relationship with residual stress, and minimum residual stress was noted at $75 \mu \mathrm{m}$ layer thickness. Process parameters have the most significant influence on mechanical properties. Therefore, it is essential to identify the optimal parameter settings. Recent developments in the SLM technique show that using a small laser beam diameter, for example, $\sim 100 \mu \mathrm{m}$, with high laser power will increase the evaporating rate at the point of processing due to the high laser intensity as well as increase the depth of melting pool; therefore, it is difficult for the gas to escape during rapid solidification process, and thus, pores form, which has a negative effect on the process as a whole (Ref 17, 18). In contrast, increasing the beam diameter to lower the laser intensity will increase the melting pool area, increasing the surface roughness of manufactured parts, also causing irregularly shaped pores, likely resulting from lack-offusion defects during the process (Ref 19). All the mentioned 
types of defects have effects on the mechanical properties of a final part.

Many studies on the mechanical properties like hardness, tensile, and fatigue of SLM samples before and after solution heat treatment have been carried out by different authors (Ref 12, 20, 21). In addition, hot isostatic pressing (HIP) treatment also was applied on as-built SLM samples in numerous studies to improve the fatigue property of the SLM part and reduce porosity (Ref 22, 23). However, combination of HIP with different post-heat treatments on the microstructure and mechanical properties of SLM specimens, aimed at improving structural integrity, microstructural and mechanical capability for different applications, has not been thoroughly investigated. The current study investigates the effect of the different cooling rates on the microstructure and hardness of the SLM Ti-6Al-4V fatigue specimens. The microstructures under different heat treatment conditions and cooling rates were determined using optical microscopy (OM), scanning electron microscopy (SEM), energy-dispersive x-ray spectroscopy (EDS) and x-ray diffraction (XRD). In addition, microhardness tests were applied to evaluate the Ti-6Al-4V structure.

\section{Experimental}

\subsection{Material and Methods}

SLM EOS M290 machine was used to create fatigue specimens. Argon gas was pumped into the EOS M290 machine's building chamber to prevent the titanium powder from oxidizing during the fabrication process. The scanning parameters were as follows: $80 \mu \mathrm{m}$ spot diameter, $0.02 \mathrm{~mm}$ overlap stripe and $30 \mu \mathrm{m}$ layer thicknesses. Three different laser power levels were employed to melt the powder at different locations to build the same sample, $370 \mathrm{~W}$ infill, 340 $\mathrm{W}$ down skin and $360 \mathrm{~W}$ up skin. The scanning process was carried out following a shell and core strategy. Firstly, the raster laser motion melted the inner layer to increase productivity, after which the contour of the layer was melted to gain surface quality and accuracy (Ref 24).

Subsequently, for each successive layer, the scanning laser was rotated by $67^{\circ}$. The samples employed in the experiment were printed horizontally and vertically in $3 \mathrm{D}$ form. The build platform was then covered with the first layer of the metal alloy powder, after which a powerful $\mathrm{CO}_{2}$ laser was employed to trace out the layer. This process was carried out for each layer where laser ultimately melted the materials and fused them until complete fatigue specimens were formed horizontally and vertically with an overall length of $94 \mathrm{~mm}$, a gauge section width of $7 \mathrm{~mm}$, a grip section width of $19 \mathrm{~mm}$ and a thickness of $2.57 \mathrm{~mm}$. Table 1 shows the chemical composition of the constructed specimens.

The specimens were placed in a vacuum furnace to undergo a stress-relief process without oxidation and avoiding deformation (Ref 25-28). Samples were then treated at $704 \pm 14{ }^{\circ} \mathrm{C}$ for $2 \pm 0.25 \mathrm{~h}$ according to ASTM F3301. Next, the samples were left to cool down in the furnace to room temperature ( 25 ${ }^{\circ} \mathrm{C}$ ) to ensure that oxidation did not occur and minimize new residual stresses. Additionally, some samples were subjected to hot isostatic pressing to reduce pores and avoid defects (Ref 29). The detailed results of only stress-relieved samples were reported previously (Ref 8 ). Next, the samples were placed in an inert atmosphere at $920{ }^{\circ} \mathrm{C}$ for $120 \pm 30 \mathrm{~min}$ and $100 \pm 5$ $\mathrm{MPa}$, after which they were cooled down under an inert atmosphere to below $425{ }^{\circ} \mathrm{C}$. The fatigue testing was then performed for both SR and SR+HIP samples. The samples were then cut from the grip section of the fatigue specimens. To evaluate the influence of HIP on porosity, the porosity of the specimens was tested and measured before and after HIP processing without the etching process to avoid any potential effect on the size and depth of the pores. In order to generate different microstructures, the samples underwent heat treatment at $930,45{ }^{\circ} \mathrm{C}$ below the $\beta$-transus temperature. This process lasted for $15 \mathrm{~min}$, after which they were cooled at different rates, including furnace cooling (FC), air cooling (AC) and water quenching (WQ). This is illustrated in Fig. 1. Finally,

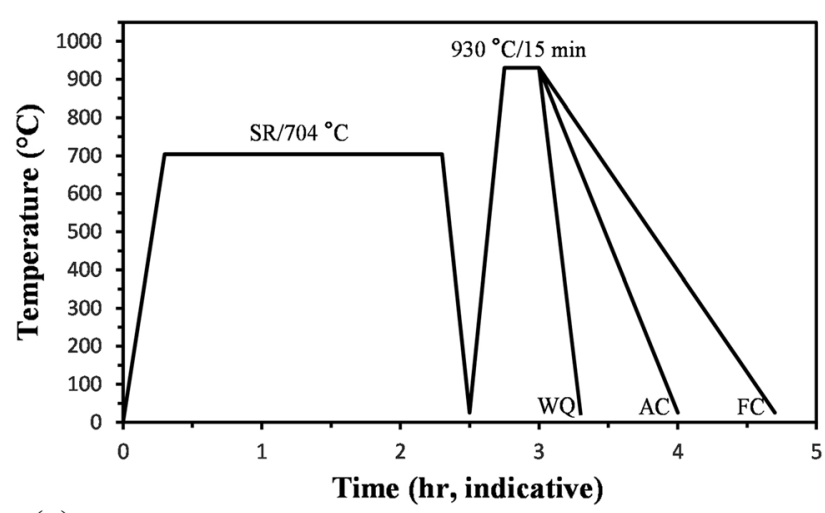

(a)

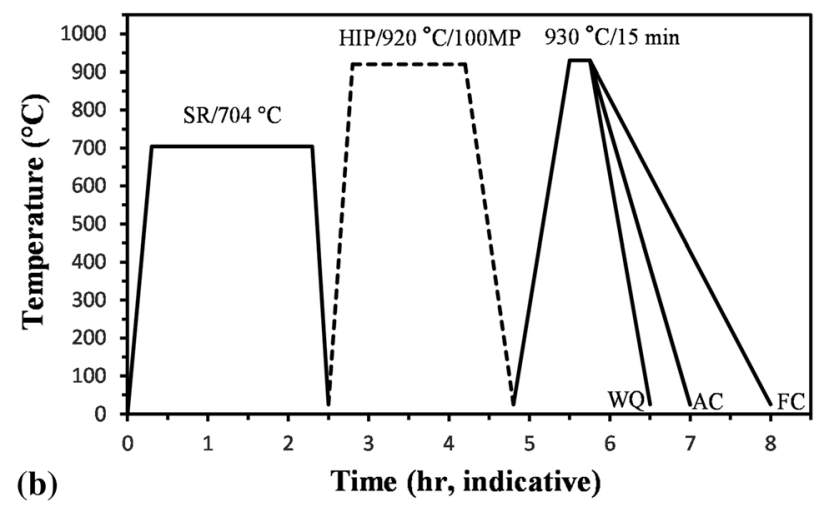

Fig. 1 Schematic representation of the heat treatment conditions employed in this experiment for Ti-6Al-4V alloy, where $\mathrm{FC}=$ furnace cooling, $\mathrm{AC}=$ air cooling, and $\mathrm{WQ}=$ water quenching

Table 1 Chemical composition of the samples built in the project (wt.\%)

\begin{tabular}{lcccccccccccccc}
\hline Element & Ti & Al & V & Fe & Cr & Cu & O & H \\
\hline wt.\% & 89.36 & 6.4 & 3.96 & 0.07 & 0.01 & 0.01 & 0.119 & 0.024 \\
\hline
\end{tabular}




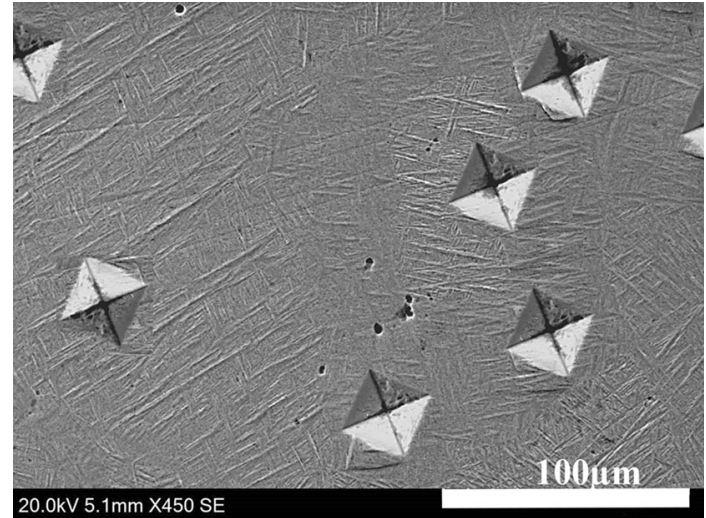

Fig. 2 SEM image of the Vickers hardness indentation obtained by applying a load of $0.30 \mathrm{~kg}$

OM, SEM, XRD and EDS analyses were performed on the microstructures

\subsection{Hardness Testing and Microstructural Characterization}

Before proceeding with any further heat treatment, the grip section of fatigue specimens was cut into eight pieces with a dimension of approximately $10 \times 10 \mathrm{~mm}$ using wire electrical discharge machining (EDM) with a $5 \mathrm{~mm} / \mathrm{min}$ cutting speed. Samples were then mechanically ground, polished down to a mirror finish and etched with Kroll's reagent. Samples were then cleaned with alcohol for 7-10 s, followed by distilled water. A Hitachi FlexSEM 1000 scanning electron microscope was used to examine the microstructure. The chemical composition of the samples was determined using EDS down to a few microns. Phase analyses were performed using the X'Pert HighScore Plus, and the fractions of phases were determined from SEM images using MIPAR image analysis software. Microhardness measurements were made using a Buehler micro-indentation hardness tester. A load of $0.30 \mathrm{~kg}$ was applied for ten seconds, with a minimum of seven indentations being performed per sample. The hardness measurement was conducted at random sites with indent size sufficiently large relative to the microstructural features concerned, as demonstrated in Fig. 2, and then, average values were calculated.

\section{Results and Discussion}

\subsection{Before Post-Heat Treatment}

According to our previous study (Ref 8), the SR specimens which did not experience any additional treatment were characterized by the microstructure of martensite containing fine needle-shaped features with lath width up to $1.2 \mu \mathrm{m}$ and microhardness value of $408 \pm 4$ HV0.3. In contrast, the SR + HIP specimens, before applying any further solution treatment, demonstrated coarser grains composed of a mixture of $\alpha$ with a typical lath width size of about $2-5 \mu \mathrm{m}$ and $\sim 6 \% \beta$ lamellar microstructure, with a reduction of volume fraction of porosity from $0.38 \pm 0.24 \%$ to $0.20 \pm 0.09$ and a microhardness value of $346 \pm 8 \mathrm{HV} 0.3$. This is owing to the larger grain size, including the transformation of needle-shaped $\alpha^{\prime}$ to lamellar $\alpha+\beta$. The driving factor is the simultaneous pressure and heat applied to the material during the HIP process, where the
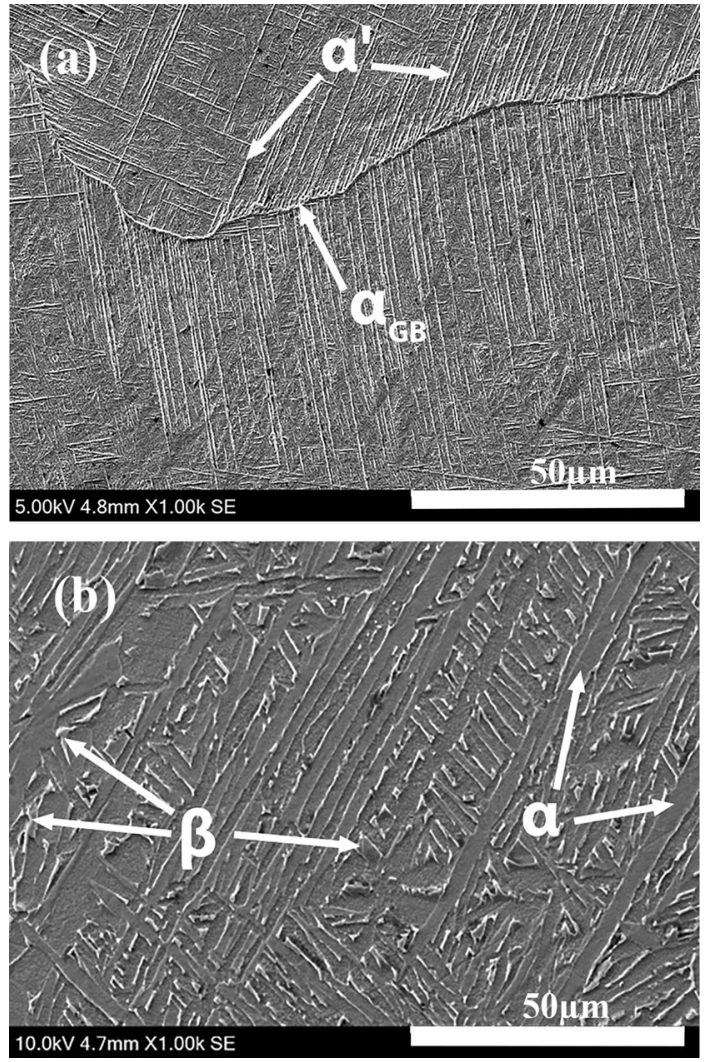

Fig. 3 SEM images of the microstructure of Ti-6Al-4V produced by SLM. (a) Only stress-relieved at $704{ }^{\circ} \mathrm{C}$, and (b) after stress relief at $704{ }^{\circ} \mathrm{C}$ and HIP treatment

appearance of the $\beta$ phase correlated positively with lower hardness (Ref 30, 31). The applied temperature is to raise the diffusivity while reducing the yield strength of the material allowing the pores to close properly. If the temperature is too high, however, undesirable amounts of grain development may occur, leading to changes in microstructure and material characteristics. In addition, the pressure works to ensure the solubility of any gas released due to collapsing pores. On the other hand, if the pressure was too low, some gases would escape to another pore vice the surface (Ref 32). Typical SEM images of the SR and SR + HIP samples are shown in Fig. 3.

\subsection{Stress-Relief Followed by Post-Heat Treatment}

The microstructural examination of the stress-relieved sample followed by solution treatment at $930{ }^{\circ} \mathrm{C}$ indicated that the quenched samples were characterized by a mixture of $\alpha$ and $\alpha^{\prime}$ phases identified as needles with size 1.8-80 $\mu \mathrm{m}$ in length and $0.3-2.4 \mu \mathrm{m}$ in width, with a microhardness value of $336 \pm$ $6 \mathrm{HV} 0.3$. This result was attributed to the fact that at $930{ }^{\circ} \mathrm{C}$, the microstructure mainly consists of $\beta$ with a small amount of $\alpha$ phase, and during quenching, that $\beta$ phase will transform into $\alpha^{\prime}$ phase. Meanwhile, the air cooling produced a structure dominated by the $\alpha$ phase with a size of up to $27.6 \mu \mathrm{m}$ in length and up to $2.5 \mu \mathrm{m}$ in width, with $\sim 7.5 \%$ of the $\beta$ phase and microhardness value of about $330 \pm 4$ HV0.3. In contrast, furnace cooling from $930{ }^{\circ} \mathrm{C}$ led to a microstructure with a coarse plate-like mixture of $\alpha$ phase with a size of up to $45 \mu \mathrm{m}$ in length and up to $4.3 \mu \mathrm{m}$ in width with $\sim 17 \%$ of the $\beta$ phase and no $\alpha^{\prime}$ martensite phase being noted as illustrated in 

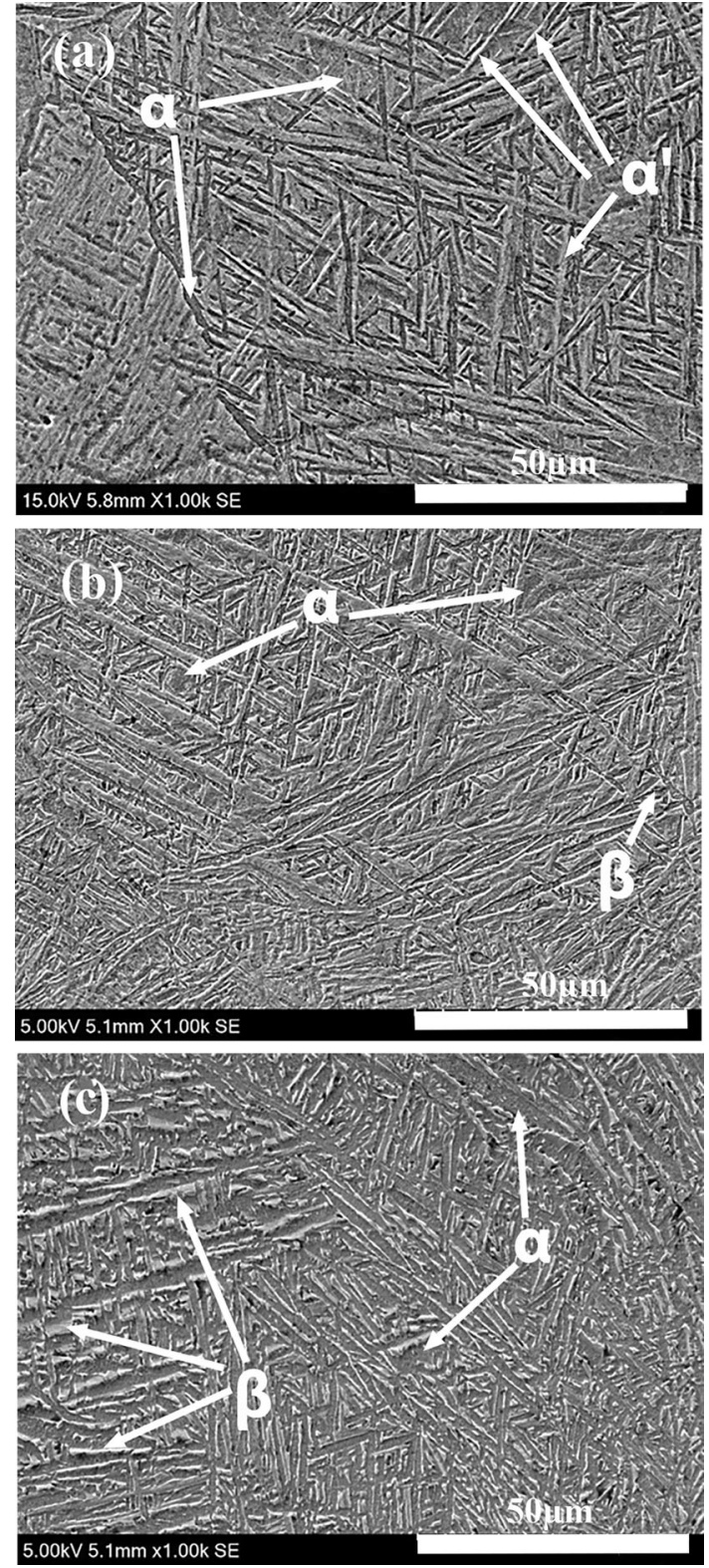

Fig. 4 SEM images of the microstructure of Ti-6Al-4V produced by SLM after stress-relief treatment at $704{ }^{\circ} \mathrm{C}$ and solution-treated at $930{ }^{\circ} \mathrm{C}$, followed by different cooling rates. (a) WQ from $930{ }^{\circ} \mathrm{C}$, (b) $\mathrm{AC}$ from $930^{\circ} \mathrm{C}$, (c) $\mathrm{FC}$ from $930{ }^{\circ} \mathrm{C}$

Fig. 4. The average hardness for this microstructure was $\sim 327$ \pm 6 HV0.3. XRD analysis validated that the microstructure of the water-quenched specimens did contain martensite and that $\beta$ emerged at lower cooling speeds (air/furnace). As can be seen in Fig. 5, the patterns indicate the presence of the $\beta$ phase after air cooling and furnace cooling, whereas only $\alpha / \alpha$ ' phase is noted with no $\beta$ phase after quenching. Compared with air cooling, the XRD peak of the $\beta$ phase was sharper following furnace cooling, most likely because of the different internal stresses associated with each process. Figure 6 provides the EDS spectra with the chemical composition in wt.\% in various regions for heat-treated samples. WQ samples show no significant difference in the chemical composition in both white and dark areas, compared with the noticeable difference in the aluminum and vanadium values after air and furnace

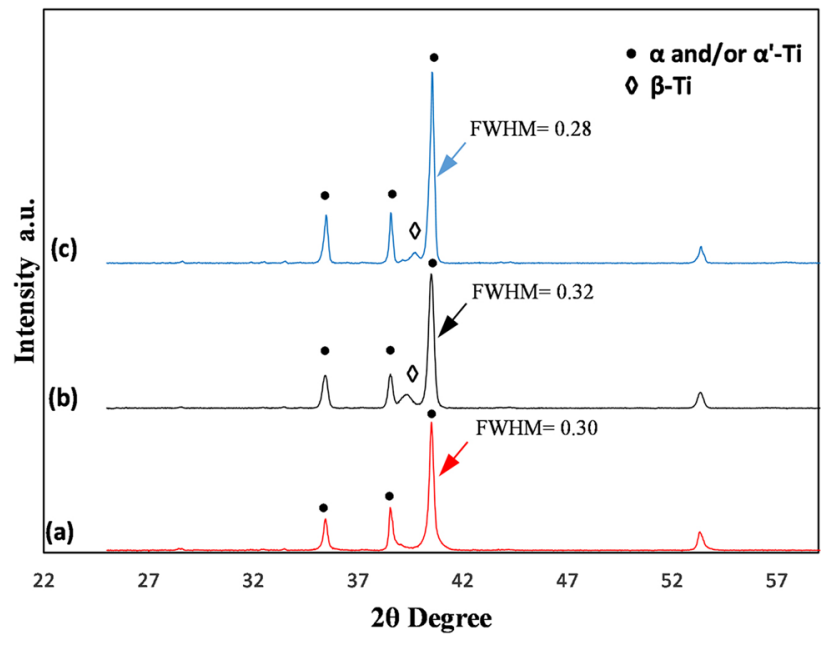

Fig. 5 XRD patterns of SLM samples after stress-relief treatment at $704{ }^{\circ} \mathrm{C}$ and solution-treated at $930{ }^{\circ} \mathrm{C}$, followed by different cooling rates. (a) WQ from $930{ }^{\circ} \mathrm{C}$, (b) $\mathrm{AC}$ from $930{ }^{\circ} \mathrm{C}$, and (c) $\mathrm{FC}$ from $930{ }^{\circ} \mathrm{C}$

cooling in the two regions. The low value of vanadium indicates that the $\alpha$ phase dominates the microstructure.

The microhardness values were compared with those quenched samples from $1015{ }^{\circ} \mathrm{C}$ studied previously (Ref 8). When the treatment temperature was decreased by $85^{\circ} \mathrm{C}$, the microhardness values decreased by $16.5 \%$ from $391 \pm 3$ HV 0.3 to $336 \pm 6 \mathrm{HV} 0.3$, while the size of martensite needles grew from 1.1 to $55 \mu \mathrm{m}$ lengths and 1.1-1.8 $\mu \mathrm{m}$ widths to $1.8-80$ lengths and 0.8-2.3 widths. This conclusion is consistent with the Hall-Petch strengthening effect, in which an increase in needle size results in a reduction in total needle boundary area, resulting in high ductility and low hardness (Ref 33,34$)$. This increase inhardness at $1015{ }^{\circ} \mathrm{C}$ might also be due to the differences in microstructure before WQ. As $1015^{\circ} \mathrm{C}$ is above $\beta$-trances, only $\beta$ phase will exist; hence, nearly $100 \%$ of $\alpha^{\prime}$ martensite will form after WQ. In contrast, at $930{ }^{\circ} \mathrm{C}$, which is below $\beta$-trances, a mixture of $\beta+\alpha$ phase will form. In this case, only the $\beta$-phase would transform after quenching into $\alpha^{\prime}$ martensite. Furthermore, the composition of $\alpha$ before WQ will be different. The aluminum content at a higher solution treatment temperature of $1015{ }^{\circ} \mathrm{C}$ is different than $930{ }^{\circ} \mathrm{C}$. Al would be more dissolved at higher solution temperature than at lower temperature. (Ref 35). Table 2 shows the comparisons of the microhardness values to those treated from $1015^{\circ} \mathrm{C}$.

\subsection{Stress-Relief and HIP Followed by Post-Heat Treatment}

As stated above, the microstructure of the SR+HIP samples consists of a mixture of $\alpha$ and $\beta$ phases. During post-heat treatment at $930{ }^{\circ} \mathrm{C}$, most of the $\alpha$ phase will transform to $\beta$ grains, and thus, microstructure will be mainly a $\beta$ phase. Following quenching, the microstructure of the samples mainly consisted of several microns of $\alpha^{\prime}$ needles with $0.8-41 \mu \mathrm{m}$ in length and up to $1 \mu \mathrm{m}$ in width with a microhardness value of $377 \pm 2 \mathrm{HV} 0.3$. Prior- $\beta /_{\mathrm{GB}}$ was observed because of the thermal gradient along the build direction, Fig. 7(a). The transformation of the $\beta$ phase into a fine $\alpha^{\prime}$ martensite after the laser melting process is due to this process' very high cooling rate. A small amount of $\beta$ was likely retained between the martensite needles. However, it would be low in volume and 


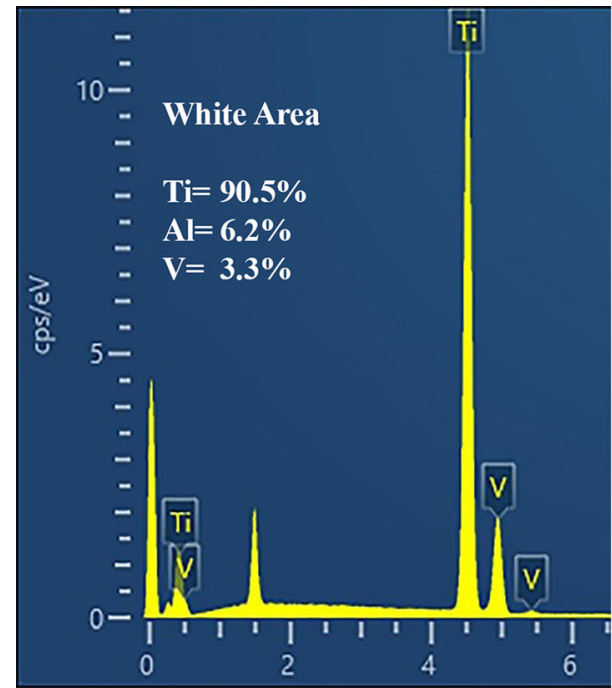

(a)

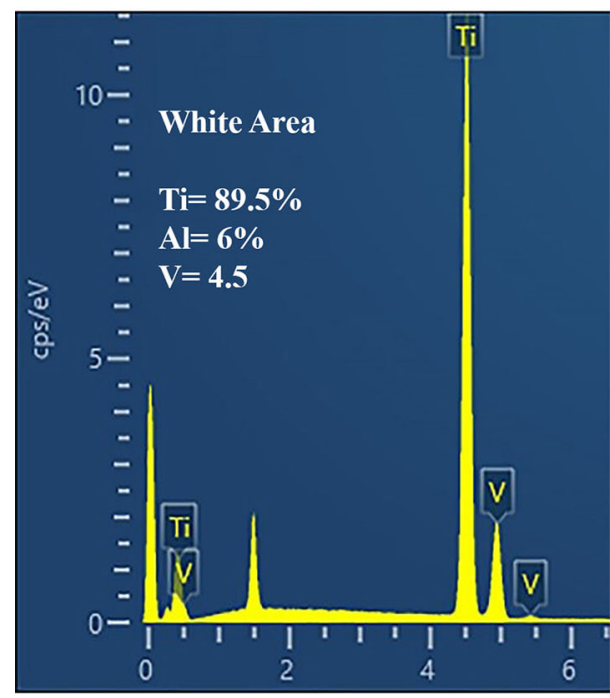

(c)

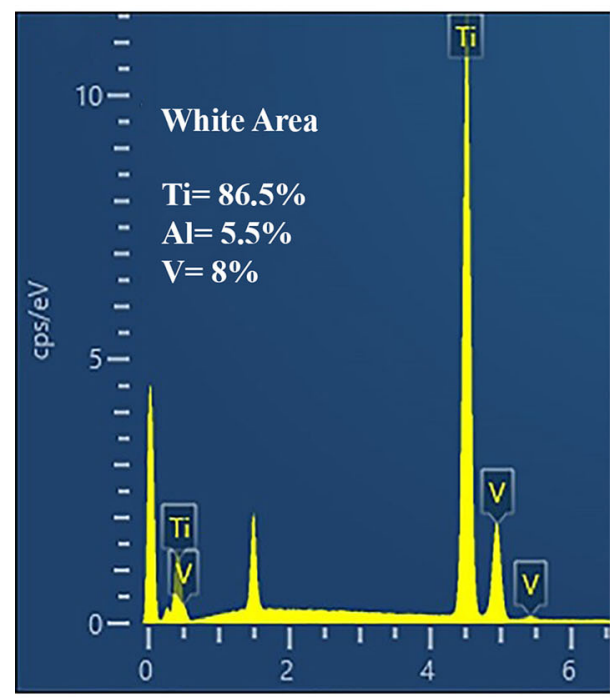

(e)

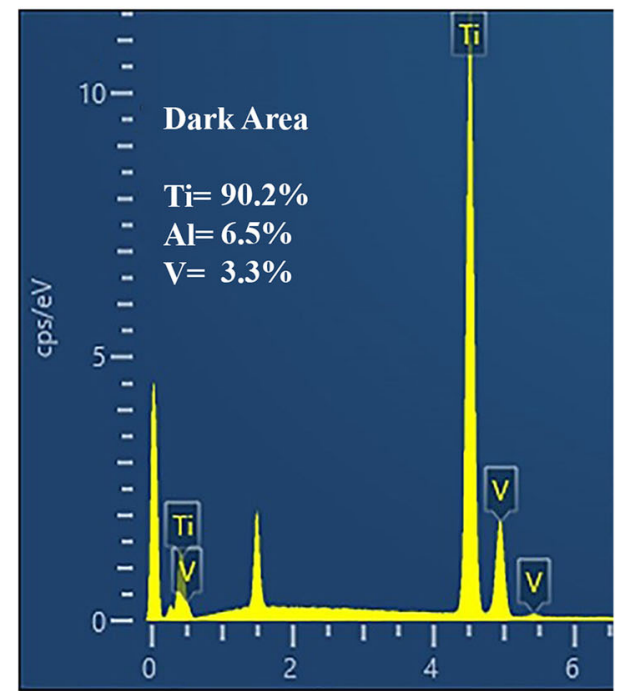

(b)

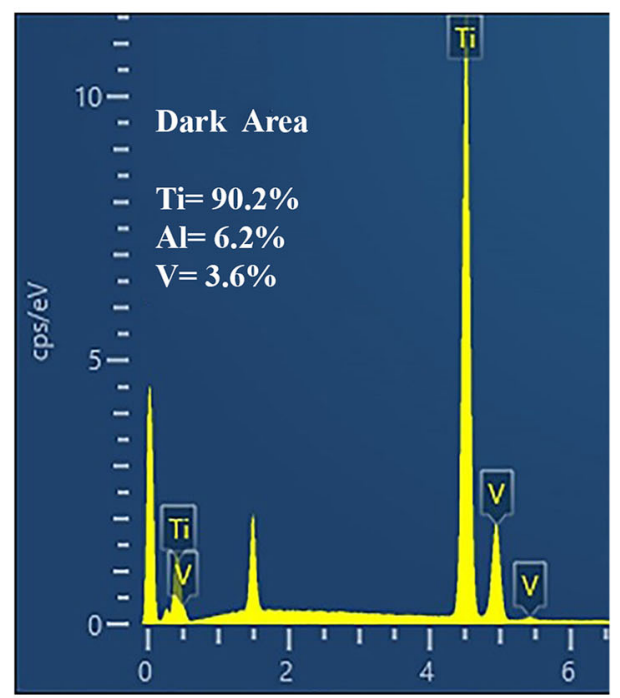

(d)

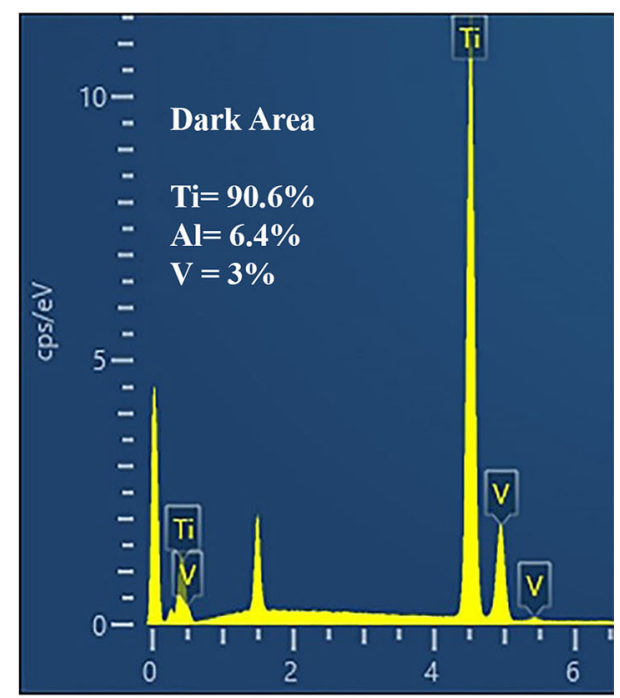

(f)

Fig. 6 EDS spectra show the composition of Ti-6Al-4V samples in wt.\% after stress-relief treatment at $704{ }^{\circ} \mathrm{C}$ and solution-treated at $930{ }^{\circ} \mathrm{C}$, followed by different cooling rates. "White" and "Dark" areas correspond to the brightness in the SEM images in Fig. 4. (a) and (b) WQ from $930{ }^{\circ} \mathrm{C}$, (c) and (d) $\mathrm{AC}$ from $930{ }^{\circ} \mathrm{C}$, and (e) and (f) $\mathrm{FC}$ from $930{ }^{\circ} \mathrm{C}$ 
Table 2 Comparisons of microstructure evolution and microhardness values after heat treatment at 930 and $1015{ }^{\circ} \mathrm{C}$ of Ti-6Al-4V produced by SLM with stress-relief treatment

\begin{tabular}{|c|c|c|c|c|c|c|}
\hline \multirow{2}{*}{$\begin{array}{l}\text { Solution temperature } \\
\text { Cooling }\end{array}$} & \multicolumn{3}{|c|}{$930^{\circ} \mathrm{C}$} & \multicolumn{3}{|c|}{$1015^{\circ} \mathrm{C}$} \\
\hline & WQ & $\mathbf{A C}$ & FC & WQ & $\mathbf{A C}$ & FC \\
\hline $\begin{array}{l}\text { Hardness (HV0.3) } \\
\text { Phase }\end{array}$ & $\begin{array}{l}336 \pm 6 \\
\alpha^{\prime}+\alpha\end{array}$ & $\begin{array}{l}330 \pm 4 \\
\alpha+7.5 \% \beta\end{array}$ & $\begin{array}{l}327 \pm 6 \\
\alpha+17 \% \beta\end{array}$ & $\begin{array}{l}391 \pm 7 \\
\alpha^{\prime}\end{array}$ & $\begin{array}{l}382 \pm 3 \\
\alpha+\text { very low content of } \beta\end{array}$ & $\begin{array}{l}356 \pm 1 \\
\alpha+8.5 \% \beta\end{array}$ \\
\hline
\end{tabular}
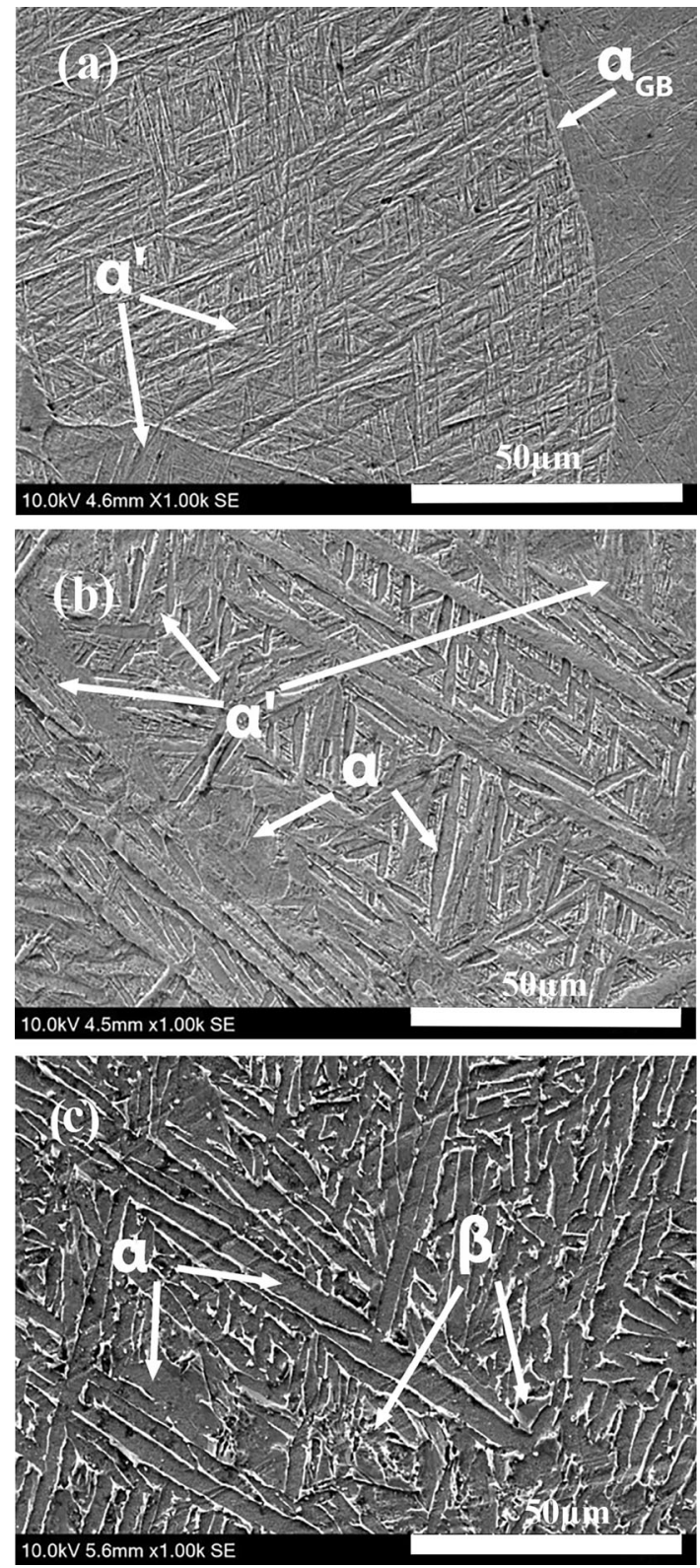

Fig. 7 SEM images of the microstructure of Ti-6Al-4V produced by SLM after stress-relief at $704{ }^{\circ} \mathrm{C}$, HIP treatment and solution treatments followed by different cooling rates. (a) WQ from $930{ }^{\circ} \mathrm{C}$, (b) $\mathrm{AC}$ from $930{ }^{\circ} \mathrm{C}$, (c) $\mathrm{FC}$ from $930{ }^{\circ} \mathrm{C}$

hardly detected. Figure 7(b) shows the microstructure after air cooling. The $\beta$-phase transformed to the $\alpha$-phase leading to a mixture of $\alpha$-lamella with up to $76 \mu \mathrm{m}$ in length and up to $5 \mu \mathrm{m}$ in width and a small amount of retained $\beta$ phase. However,

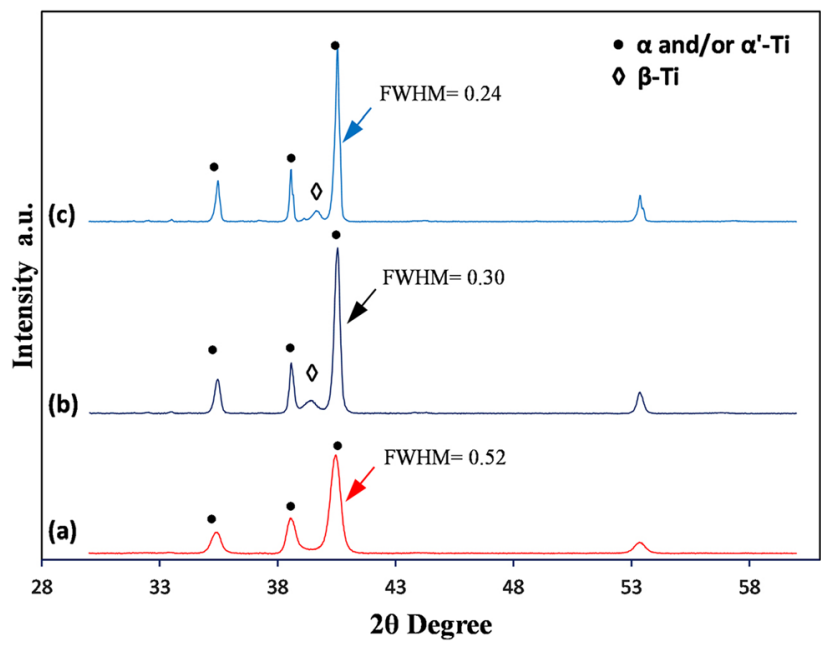

Fig. 8 XRD patterns of SLM samples after stress-relief at $704{ }^{\circ} \mathrm{C}$, HIP treatment and solution treatments followed by different cooling rates. (a) WQ from $930{ }^{\circ} \mathrm{C}$, (b) $\mathrm{AC}$ from $930{ }^{\circ} \mathrm{C}$ and (c) $\mathrm{FC}$ from $930{ }^{\circ} \mathrm{C}$

there are some fine needles of the $\alpha^{\prime}$ phase left in the microstructure.

Meanwhile, in the case of the specimens after furnace cooling, a complete transformation of $\beta$ to $\alpha+\beta$ mixture was observed, and the pattern of $\alpha$ lath was coarser up to $62.8 \mu \mathrm{m}$ in length and $5.6 \mu \mathrm{m}$ in width, with $\sim 14 \%$ of $\beta$ as illustrated in Fig. 7(c). Vickers microhardness values decreased as the cooling rate decreased, reaching a minimum of $322 \pm 4 \mathrm{HV} 0.3$ with a $17 \%$ decrease after furnace cooling and $12 \%$ after air cooling to $336 \pm 3 \mathrm{HV} 0.3$ to the water-quenched samples. XRD analysis validated that the microstructure of the waterquenched specimens did contain martensite and that $\beta$ emerged at lower cooling speeds (air or furnace cooling). As can be seen in Fig. 8, the patterns indicate the presence of the $\beta$ phase at around $2 \theta=39.3^{\circ}$ and $39^{\circ}$ after air cooling and furnace cooling, respectively, whereas the only $\alpha / \alpha^{\prime}$ phase is noted, with no $\beta$ phase after quenching. Comparing the peaks intensity and its full width at half maximum (FWHM) value with those samples not exposed to HIP treatment illustrated in Fig. 5, the peaks of the WQ specimen are wider following HIP treatment while no significant difference after air and furnace cooling. This wider peak after WQ may indicate higher internal stress and a smaller grain size. Figure 9 shows the EDS spectra presenting the measured chemical composition in the different regions on the microstructure. The result shows a higher fraction of vanadium in the white area after air and furnace cooling indicating the formation of $\beta$ phase.

By comparing the results of solution-treated microstructure and hardness with and without the HIP process, an exciting 

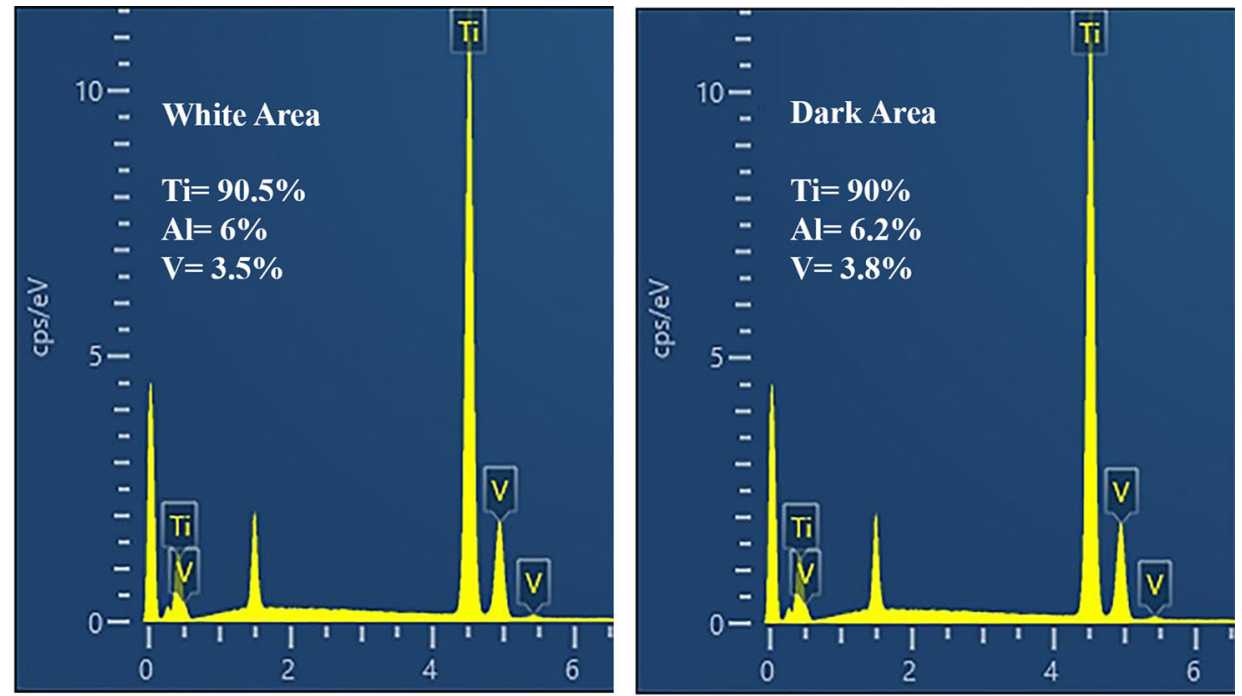

(a)

(b)
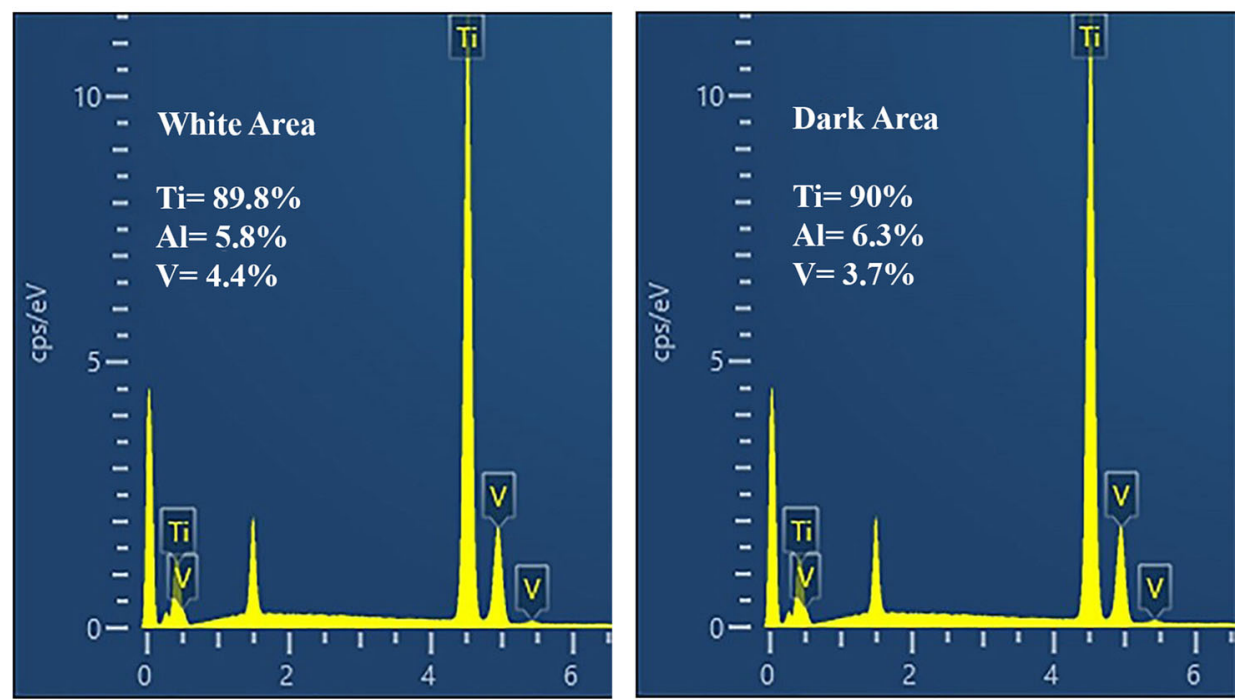

(c)

(d)
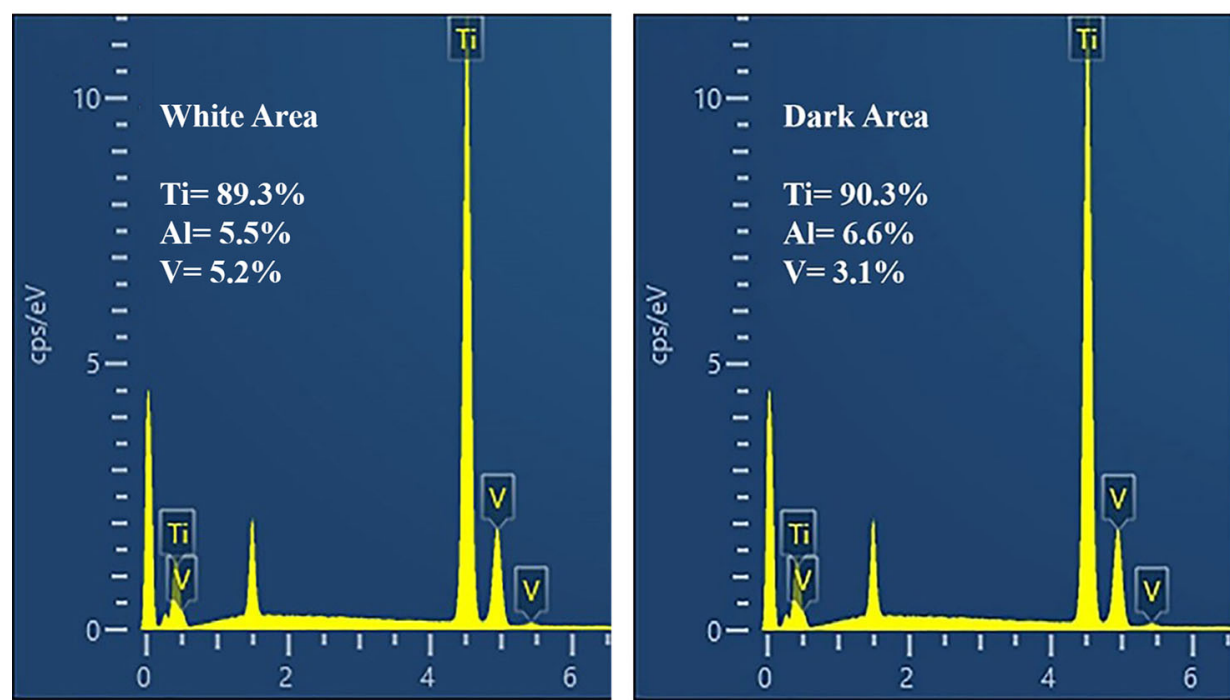

(e)

(f)

Fig. 9 EDS spectra and the composition in wt.\% of Ti-6Al-4V samples after stress-relief treatment at $704{ }^{\circ} \mathrm{C}$, HIP treatment and solution treatment at $930{ }^{\circ} \mathrm{C}$ followed by different cooling rates. "White" and "Dark" areas correspond to the brightness in the SEM images in Fig. 7. (a) and (b) WQ from $930{ }^{\circ} \mathrm{C}$, (c) and (d) $\mathrm{AC}$ from $930{ }^{\circ} \mathrm{C}$, and (e) and (f) $\mathrm{FC}$ from $930{ }^{\circ} \mathrm{C}$ 
relationship was observed between the heat treatments and their resulting hardness values. The hardness value of the solutiontreated samples at $930{ }^{\circ} \mathrm{C}$ after the HIP process decreased from $377 \pm 2 \mathrm{HV} 0.3$ after water quenching to $336 \pm 3 \mathrm{HV} 0.3$ after air cooling and then slightly decreased to $322 \pm 4 \mathrm{HV} 0.3$ after furnace cooling. The increase inhardness value after quenching was due to the formation of $\alpha^{\prime}$ martensite with a much finer microstructure. In contrast, samples not exposed to HIP processing show a lower microhardness value; $336 \pm 6 \mathrm{HV}$ after water quenching, $330 \pm 4 \mathrm{HV}$ after air cooling and $327 \pm$ $6 \mathrm{HV}$ after furnace cooling. This is related to the smaller grain size obtained after HIP followed by solution treatment compared to those solution-treated samples not preceded by the HIP. A smaller grain size means more grain boundaries, so the hardness value is higher. It might also be due to the lower porosity level after HIP illustrated in our previous study (Ref 8).

\section{Conclusion}

- The microstructural examination of the stress-relieved samples followed by solution treatment at $930{ }^{\circ} \mathrm{C}$ indicated that the quenched samples were characterized by a mixture of $\alpha$ and large needles of $\alpha^{\prime}$ phase. Air cooling produced a structure dominated by the $\alpha$ phase, with a small amount of the $\beta$ phase being observed. Furnace cooling from $930{ }^{\circ} \mathrm{C}$ exhibited a microstructure with a coarse plate-like mixture of $\alpha$ phase and $\sim 17 \%$ of the $\beta$ phase with no $\alpha^{\prime}$ martensite phase being noted.

- The stress-relieved and HIPed specimens demonstrated coarse grains composed of a lamellar $\alpha+6 \% \beta$ microstructure.

- The stress-relieved and HIPed specimens exposed to postheat treatment at $930{ }^{\circ} \mathrm{C}$ followed by quenching exhibited a microstructure of needle-like martensite microstructure, and $\alpha_{\mathrm{GB}}$ was observed. After air cooling, the $\beta$-phase transformed to the $\alpha$-phase leading to a mixture of $\alpha+\beta$ phase and some needles of $\alpha^{\prime}$ phase left in their microstructures. After furnace cooling, a complete transformation of $\beta$ to $\alpha+\beta$ mixture was observed, and the pattern of $\alpha$ lath was formed.

- The solution-treated and water-quenched samples with the HIP processing have a higher hardness value comparing to those without the HIP, due to grain size effect and the reduced porosity.

\section{Open Access}

This article is licensed under a Creative Commons Attribution 4.0 International License, which permits use, sharing, adaptation, distribution and reproduction in any medium or format, as long as you give appropriate credit to the original author(s) and the source, provide a link to the Creative Commons licence, and indicate if changes were made. The images or other third party material in this article are included in the article's Creative Commons licence, unless indicated otherwise in a credit line to the material. If material is not included in the article's Creative Commons licence and your intended use is not permitted by statutory regulation or exceeds the permitted use, you will need to obtain permission directly from the copyright holder. To view a copy of this licence, visit http://creativecommons.org/licenses/by/4.0/.

\section{References}

1. M. Collan and K.-E. Michelsen Eds., Technical, Economic and Societal Effects of Manufacturing 40: Automation Adaption and Manufacturing in Finland and Beyond, Springer, 2020

2. M. Korpela, N. Riikonen, H. Piili, A. Salminen and O. Nyrhilä, Additive Manufacturing: Past, Present, and the Future, Technical, Economic and Societal Effects of Manufacturing 40: Automation Adaption and Manufacturing in Finland and Beyond. M. Collan, K.-E. Michelsen Ed., Springer, 2020

3. D. Jafari and W.W. Wits, The Utilisation of Selective Laser Melting Technology on Heat Transfer Devices for Thermal Energy Conversion Applications: A Review, Renew. Sustain. Energy Rev., 2018, 91, p $420-442$.

4. Y. Polsky, K.O. Armstrong, C. Price, J.-C. Su, A. Wang, and S. Porse, Study of Additive Manufacturing Application to Geothermal Technologies, Oak Ridge Natl. Lab., 2020

5. N. Singh, P. Hameed, R. Ummethala, G. Manivasagam, K.G. Prashanth and J. Eckert, Selective Laser Manufacturing of Ti-Based Alloys and Composites: Impact of Process Parameters, Application Trends, and Future Prospects, Mater. Today Adv., 2020, 8, p 100097.

6. K. Karolewska and B. Ligaj, Comparison Analysis of Titanium Alloy Ti6A14V Produced by Metallurgical and 3D Printing Method, AIP Conf, Proc., 2019, 2077(1), p 20025.

7. H. Zhang, D. Dengke, S.U. Shaopu and C. An, Experimental Study of Effect of Post Processing on Fracture Toughness and Fatigue Crack Growth Performance of Selective Laser Melting Ti-6Al-4V, Chinese J. Aeronaut., 2019, 32(10), p 2383-2393.

8. N. Eshawish, S. Malinov, W. Sha and P. Walls, Microstructure and Mechanical Properties of Ti-6Al-4V Manufactured by Selective Laser Melting after Stress Relieving, Hot Isostatic Pressing Treatment, and Post-Heat Treatment, J. Mater. Eng. Perform., 2021, 30, p 5290-5296.

9. S. Gorsse, C. Hutchinson, M. Gouné and R. Banerjee, Additive Manufacturing of Metals: A Brief Review of the Characteristic Microstructures and Properties of Steels, Ti-6Al-4V and High-Entropy Alloys, Sci. Technol. Adv. Mater., 2017, 18(1), p 584-610.

10. X. Tan, Y. Kok, Y.J. Tan, G. Vastola, Q.X. Pei, G. Zhang, Y.-W. Zhang, S.B. Tor, K.F. Leong and C.K. Chua, An Experimental and Simulation Study on Build Thickness Dependent Microstructure for Electron Beam Melted Ti-6Al-4V, J. Alloys Compd., 2015, 646, p 303-309.

11. D. Agius, K.I. Kourousis and C. Wallbrink, A Review of the As-Built SLM Ti-6Al-4V Mechanical Properties towards Achieving Fatigue Resistant Designs, Metals, 2018, 8(1), p 75.

12. J. He, D. Li, W. Jiang, L. Ke, G. Qin, Y. Ye, Q. Qin and D. Qiu, The Martensitic Transformation and Mechanical Properties of Ti6A14V Prepared via Selective Laser Melting, Materials, 2019, 12(2), p 321.

13. L. Zhang and H. Attar, Selective Laser Melting of Titanium Alloys and Titanium Matrix Composites for Biomedical Applications: A Review, Adv. Eng. Mater, 2016, 18(4), p 463-475.

14. N. Dai, L.C. Zhang, J. Zhang, Q. Chen and M. Wu, Corrosion Behavior of Selective Laser Melted Ti-6Al-4 V Alloy in NaCl Solution, Corros. Sci., 2016, 102, p 484-489.

15. H. Ali, H. Ghadbeigi, F. Hosseinzadeh, J. Oliveira and K. Mumtaz, Effect of Pre-Emptive in Situ Parameter Modification on Residual Stress Distributions within Selective Laser-Melted Ti6A14V Components, Int. J. Adv. Manuf. Technol., 2019, 103(9-12), p 4467-4479.

16. H. Ali, H. Ghadbeigi and K. Mumtaz, Processing Parameter Effects on Residual Stress and Mechanical Properties of Selective Laser Melted Ti6Al4V, J. Mater. Eng. Perform., 2018, 27(8), p 4059-4068.

17. W. Shi, Y. Liu, X. Shi, Y. Hou, P. Wang and G. Song, Beam Diameter Dependence of Performance in Thick-Layer and High-Power Selective Laser Melting of Ti-6Al-4V, Materials, 2018, 11(7), p 1237.

18. C. Pauzon, E. Hryha, P. Forêt and L. Nyborg, Effect of Argon and Nitrogen Atmospheres on the Properties of Stainless Steel 316 L Parts Produced by Laser-Powder Bed Fusion, Mater. Des., 2019, 179, p 107873. 
19. H. Eskandari Sabzi and P.E.J. Rivera-Díaz-del-Castillo, Defect Prevention in Selective Laser Melting Components: Compositional and Process Effects, Materials, 2019, 12(22), p 3791.

20. A. Popovich, V. Sufiiarov, E. Borisov and I.A. Polozov, Microstructure and Mechanical Properties of Ti-6Al-4V Manufactured by SLM, Key Eng. Mater, 2015, 651, p 677-682.

21. M. Shunmugavel, A. Polishetty and G. Littlefair, Microstructure and Mechanical Properties of Wrought and Additive Manufactured Ti-6Al4 V Cylindrical Bars, Procedia Technol., 2015, 20, p 231-236.

22. S. Leuders, M. Thöne, A. Riemer, T. Niendorf, T. Tröster, H.A. Richard and H.J. Maier, On the Mechanical Behaviour of Titanium Alloy TiAl6V4 Manufactured by Selective Laser Melting: Fatigue Resistance and Crack Growth Performance, Int. J. Fatigue, 2013, 48, p 300-307.

23. A. Cutolo, C. Elangeswaran, C. de Formanoir, G.K. Muralidharan, and B. Van Hooreweder, (2019) Effect of Heat Treatments on Fatigue Properties of Ti-6Al-4V and 316L Produced by Laser Powder Bed Fusion in As-Built Surface Condition, TMS 2019 148th Annual Meeting \& Exhibition Supplemental Proceedings, Springer, pp 395405

24. R. Poprawe, C. Hinke, W. Meiners, J. Schrage, S. Bremen and S. Merkt, SLM production systems: recent developments in process development, machine concepts and component design, Advances in production technology. C. Brecher Ed., Springer, 2015, p 49-65

25. A.P. Singh, F. Yang, R. Torrens and B. Gabbitas, Heat Treatment, Impact Properties, and Fracture Behaviour of Ti-6Al-4V Alloy Produced by Powder Compact Extrusion, Materials, 2019, 12(23), p 3824.

26. B. Yan, H. Li, J. Zhang and N. Kong, The Effect of Initial Annealing Microstructures on the Forming Characteristics of Ti-4Al-2V Titanium Alloy, Metals, 2019, 9(5), p 576.

27. S. Luthfiyah, A. Faridh and B. Soegijono, The Effect of Vacuum Quenching on Corrosion and Hardness of the Surface of SKD61 Steel, IOP Conf. Ser. Mater. Sci. Eng., 2019, 694(1), p 12033.
28. J.D. Matthew Jr, Heat Treating Titanium and Its Alloys, Heat Treat. Prog. pp 47-57

29. S. Tammas-Williams, P.J. Withers, I. Todd and P.B. Prangnell, The Effectiveness of Hot Isostatic Pressing for Closing Porosity in Titanium Parts Manufactured by Selective Electron Beam Melting, Metall. Mater. Trans. A, 2016, 47(5), p 1939-1946.

30. J. Zhang and Y.-G. Jung Eds., Additive Manufacturing: Materials Processes Quantifications and Applications, Butterworth-Heinemann, 2018

31. M. Neto, D. Hall, N. Frisch, A. Fischer, J. Jacobs and R. Pourzal, Is TI6AL-4V Alloy Always the Same in Orthopaedic Implants?, Orthop. Proc., 2021, 103(1), p 40.

32. B. Baker and K. Wisdom, Additively Manufactured Ti-6Al4V before and after Hot Isostatic Pressing, World J. Eng. Technol., 2021, 9(2), p 268-284.

33. B. Fu, C. Pei, H. Pan, Y. Guo, L. Fu and A. Shan, Hall-Petch Relationship of Interstitial-Free Steel with a Wide Grain Size Range Processed by Asymmetric Rolling and Subsequent Annealing, Mater. Res. Express, 2020, 7(11), p 116516.

34. S.-H. Whang Ed., Nanostructured Metals and Alloys: Processing Microstructure Mechanical Properties and Applications, Elsevier, 2011

35. I.N. Damisih, J. Jujur, S. Agustanhakri and D.H. Prajitno, Characteristics Microstructure and Microhardness of Cast Ti-6Al-4V ELI for Biomedical Application Submitted to Solution Treatment. AIP conference proceedings, 2018, 1964, 20037

Publisher's Note Springer Nature remains neutral with regard to jurisdictional claims in published maps and institutional affiliations. 